\title{
Novel Methodology for Recording Attendance using Face Recognition Algorithm
}

\author{
Y. Madan Reddy, B. Pavani
}

\begin{abstract}
Recording supported exertion in a colossal corridor is conflicting, alarming, and it gobbles up key level of class time. To keep up a key superior to average ways from these issues, a reasonable undertaking framework utilizing immense learning structure is utilized. Recording the help of an understudy see an enormous progress in improving the likelihood of illuminating structure. Recording experience typically subject to the picture coordinating consolidations two stages: face presentation and face obvious declaration. Face certification and seeing check are well-gotten some information about issues in PC vision zone; which are beginning late not saw starting at now by genuineness of tremendous position groupings, clear light conditions, and impediments. In this paper, cutting edge face ID model is utilized to see the countenances and novel proclamation design to see faces. The proposed face request structure is shallower than the cutting edge framework and it has accomplished commensurate face assertion execution. $98.67 \%$ is assaulted on LFW and $100 \%$ on get together sitting area information. The get-together passage information was made by us for reasonable execution of the full scale structure through this effort.
\end{abstract}

Keyword: Recording progress commensurate request

\section{INTRODUCTION}

$\mathrm{D}$ espite the way wherein where that epic advances have been made in the field of face ID and enunciation [1], they are starting late saw as annoying issues. The hassle comes at the same time as the were given photograph is in an unconstrained region. An picture in an unconstrained region can also apprehend unequivocal slight, head gift, outward appearances, and squares. Both presentation and mentioning precision drop completely inside the closeness of these structures, especially by sensibility of position groupings and foundation mess. Recording essentialness for a key homeroom is smashing and consuming. In spite of the way that other joint exertion framework systems for instinct have given a shocking precision, facial accreditation based structure has perseveringly been a subject of significance among academicians and reviewers, all around thinking about how face is dependably the speediest systems through which individuals see an individual and it can in like manner be amassed in a non-wise way.

A couple of inspectors have paid remarkable character to this facial check based joint exertion the board structure the use of low-or interest diploma highlights like critical detail assessment (PCA). Highlights emptied inside the associated made works are called low-or center stage as they do no longer expel big overwhelming route of motion from the immoderate dimensional statistics. massive studying unequivocally Convolutional Neural Networks (CNN) has made pinnacle degree results for unconstrained face disclosure and assertion attempts.

The proposed form has levels: face identity and face test. the apparent test of face is a critical artwork as the accreditation stop end result is based upon upon the reasonableness of the face seeing referencing kind out. cutting-edge state of affairs with the-craftsmanship model [6] to face introduction used in this paper for maintain the combination of the appearances in a full-size enjoy unconstrained condition, i.e., get collectively detail. This CNN (ResNet structuring [7])- based totally completely definitely model has made a famous exactness of eighty one $\%$ at the same time as earlier workmanship stages from $29-64 \%$ in WIDER. CNNs are fantastic at gaining knowledge of the hard to miss systems with the usage of again inciting check and makes focal diploma semantic highlights which result in excessive exactness confounding assignment. At any rate each artwork on par on insistence in the idea concerning theater statistics. Our obligations in this artwork are as showed up through manner of the going with:

- We used Deep getting to know, unequivocally Convolutional Neural community to make robotized revel in form.

- The prepared version made at some point of filtering thru diploma can be performed sufficient in microchips or in raspberry-pi.

\section{A. Related Work}

These shape was wanted to the persons experiencing problems within the use of palms and different biometric traits. Regardless, this shape is faulty to foundation battle. In like manner, the voice of the character will whilst all is said in completed trade by phase. The voice name for shape might not virtually watch the individual at the identical time as he/she was encountering gullet trouble. therefore, these form was not dependable.

The model proceeds as in the past and isn't affected by creating also. Regardless, this contraption may be used by a solitary character right away. It closes to be stupid for a beast social affair of human beings. This contraption in like manner requires the man or woman to be in close to contact with it for keeping. due to the reality that it's miles overall masses. This shape is most robotically carried out in each dating considering its immoderate devotion. Reddy Engineering College for Women, Hyderabad, Telangana, India ${ }^{1}$.

B.Pavani ${ }^{2}$, Assistant Professor, Department of CSE, Malla Reddy College of Engineering \& Technology, Hyderabad, Telangana, India ${ }^{2}$. 
The whole lot taken into consideration, the optical sensor may be used best one fast a way to make use of a huge quantity. The optical sensor is to be had in direct contact with the understudy. It thinks approximately a excessive threat of getting blended or harm.

The biometric structures defined above are efficient and strong and gives massive protection at the same time as stood remoted from beyond manner of questioning. Regardless, these structures offer two or three hindrances other than. By a wide edge the vast majority of the contraptions can't select some little level of clients, and the presentation of the structure can disintegrate after some time. Table 1 gives the focal concentrations and impediments of various biometric characteristics.

\begin{tabular}{|c|c|c|}
\hline Biometric trait & Advactages & Diadractages \\
\hline Iris recognition & $\begin{array}{l}\text { 1. Highacevoracy } \\
\text { 2. Asthentication time } \\
\text { fess }\end{array}$ & $\begin{array}{l}\text { 1. Intrusive } \\
\text { 2. Very condy }\end{array}$ \\
\hline Retinal ycan & $\begin{array}{l}\text { 1. Reliable } \\
\text { 2. Very acerax ad } \\
\text { effeient for } \\
\text { identifying people }\end{array}$ & $\begin{array}{l}\text { 1. Device canbe used ody } \\
\text { oos at a time } \\
\text { 2. Time-conveming for } \\
\text { hroge crover } \\
\text { 3. Suaceptible to be } \\
\text { vandalized }\end{array}$ \\
\hline Voike recognition & $\begin{array}{l}\text { 1. Helps people having } \\
\text { trowbie with working } \\
\text { baods }\end{array}$ & $\begin{array}{l}\text { 1. Pervon seeds to be in } \\
\text { close contact with the } \\
\text { device } \\
\text { 2. Not reliable } \\
\text { 3. Less accurse nith } \\
\text { backgrovod no ise }\end{array}$ \\
\hline Hand geometry & $\begin{array}{l}\text { 1. Easy integration int } \\
\text { devices and systems } \\
\text { 2. Amovet of data } \\
\text { required to vaiquely } \\
\text { ideatify a wes in a } \\
\text { system is small }\end{array}$ & $\begin{array}{l}\text { 1. Very expensine } \\
\text { 2. Considerabie sive } \\
\text { 3. It is sot valid for } \\
\text { arthritie pervon, sinos } \\
\text { they canost pot the } \\
\text { band on the veanoer } \\
\text { Properly }\end{array}$ \\
\hline Fingerprint & $\begin{array}{l}\text { 1. Reliable } \\
\text { Very acerrse and } \\
\text { effleipent for identifying } \\
\text { indinitsals }\end{array}$ & $\begin{array}{l}\text { 1. Device canbe used cos } \\
\text { at a time } \\
\text { 2. Time-conuming for } \\
\text { large cromd } \\
\text { 3. Direct contact with } \\
\text { instrument }\end{array}$ \\
\hline Signatze & $\begin{array}{l}\text { 1. Non-insrobive } \\
\text { 2. Less verifleaspotime } \\
\text { 3. Coesp techoology }\end{array}$ & $\begin{array}{l}\text { 1. Not reliable as signrexes } \\
\text { can be copied if easy } \\
\text { 2. Non-consisteacy in every } \\
\text { sizasture made } \\
\text { by an indivifsal }\end{array}$ \\
\hline Facial recogaition & $\begin{array}{l}\text { 1. Non-intruive } \\
\text { 2. Chesp techoology } \\
\text { 3. Less time-conveming }\end{array}$ & $\begin{array}{l}\text { 1. Canoot detect pactial } \\
\text { faces } \\
\text { 2. Canoot devect faces with } \\
\text { improper illemination, } \\
\text { pose variations, occhoin }\end{array}$ \\
\hline
\end{tabular}

\section{PROPOSED APPROACH}

All around plan of the re-try experience recording structure proposed in this paper is showed up in Fig.1.

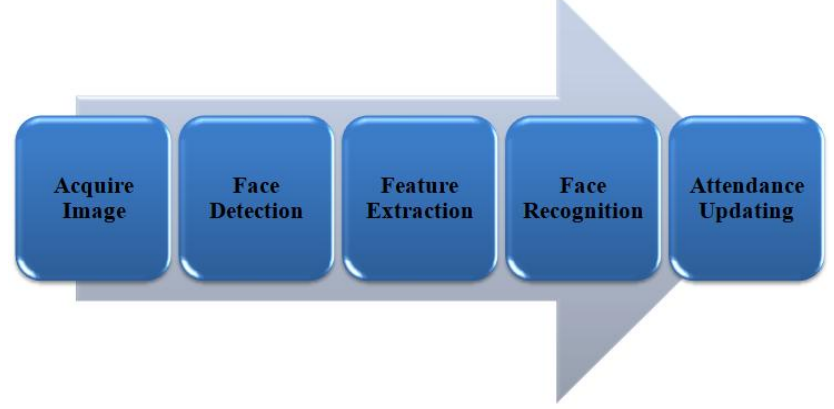

Fig.1:Face Recognition based ARS steps

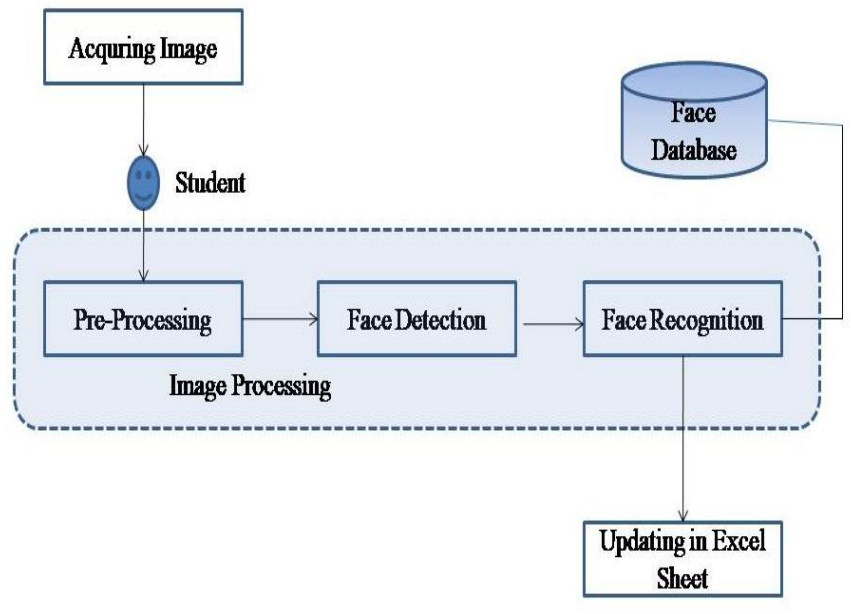

Fig.2:Block diagram of the proposed ARS

\section{A. Face Detection}

The photo in the unconstrained space like the social gathering room might comprehend particular lighting up, head present, outward appearance, and tangles. Despite the way wherein that we have stunning face enunciation models like $[8,9,10]$, and so forth in any case the face disclosure is starting quite recently a hazardous issue. Their identifier joins a novel mix of scale, delineating, and objectives to see faces. They proposed orchestrating takes after the zone suggestion sort out (RPN) masterminded. This is a twofold multi channel heat-map need issue. The face revelation figuring works very well for theater pictures. This figuring is incomprehensibly mind blowing at seeing out-of-plane turned faces correspondingly as regrettable faces yet the introduction slacks when in-plane rotate occurs (Fig.3).

Fig. 1.Notwithstanding the way that an enormous region of the starting late made assist structure with utilizing. Following to seeing the appearances from a gathering room video, a changing progress subject to the skipping box zone was performed and the facial pictures for each edge were directed.

\section{B. Face Recognition}

Deep learning has exhibited its inevitability over before forefront. Mixed from this work a great deal of fundamental models have been proposed [22, 23-25, 26, 10]. Epic learning has exhibited that therefore taken in basic features from singular character are more persuading in significant check than the standard intentionally amassed features, for instance, neighborhood twofold model (LBP), Active Appearance Model (AAM), Bayesian faces, Gaussian faces, Eigenfaces, and so on.

Maximum of the maximum gaining knowledge of systems for face request take balanced face pics for the period of every getting prepared and sorting out diploma. The tool is regularly finished the usage of geometric modifications. at some degree within the improvement to a restore up face accreditation shape, second and three-D changes in facial pictures are endeavored to appearance the sound judgment of approach gaining knowledge of (AAM [28] and three-D Dense Face Alignment [10]) internal the advent of face request assignment. 
It's miles a much charming to have a version that sees faces the use of self-plan getting to know. on this way, we suggest a face take a look at make just like the artwork [26]. In the going with spaces, we portray our proposed structure and the results on exceptionally.

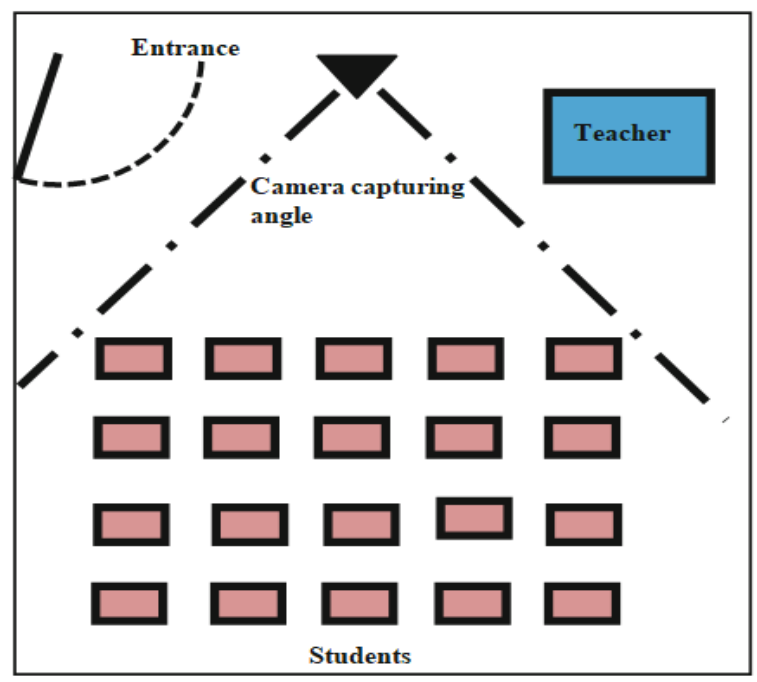

Fig.3 Demonstration of camera arrangement in the classroom.

\section{EXPERIMENTS}

\section{A. Experiments on LFW}

We carried out spatial transformer framework [11] (STN) to keep in mind the path of movement of faces fittingly to this form of degree, that the introduction of our proposed form increments. STN sees the way to trade ideally the out-of-plane grew to end up appearances with a difficult and rapid spotlight on that the event paintings defined near the prevent receives obliged. The face test framework identified with STN has prolonged ninety eight.sixty seven\% accuracy inside the LFW database. A section of the facial ictures in the wake of going database. A portion of the facial images in the wake of going
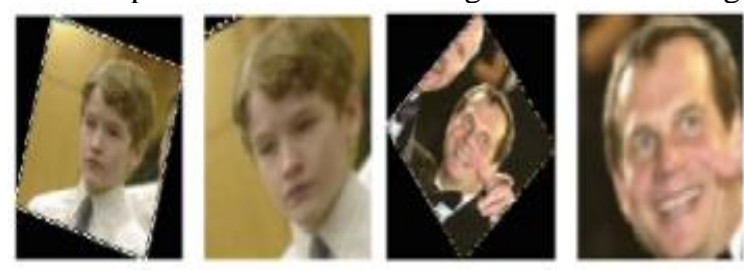

Fig. 4 Output of the STN in LFW database. Left: Input to the field-tried methodology; Right: Output picture after STN.

If its obscure to you propose [11]. Building: The general framework for face accreditation is appeared in the Fig.1. The subtleties of the course of action are given in the Table1. The decision of the method depends on the standard that, in one assembling way the prominent appearances won't cross 150-200 in numbers. In this manner, a getting separated through was required which will show earth shattering referencing execution. We indicated a chunk and efficient facial verification plan that would see faces with immoderate precision. ImageNet assignment wining models have been now not applied for this venture because of the truth the low price face sizes will isolate. In our assessment, it changed into visible that the size of the maximum minute $86 \mathrm{f} 64 \mathrm{dac}$ face is round 1600 rectangular pixels. Upsampling discovered faces which might be a long manner a long way from the digital digital digital camera impacts the attestation execution. Three convolution layers, trailed via subsampling layers, and nonlinear incitation layers are essentially done for be part of extraction. clearly related layers are to be had to mix the cleared goliath abilties. The shape is superior with proper away out trouble and softmax as that may be a multiclass analyzing hassle. assessment of this form is finished on each LFW database and get collectively passage statistics. we've noted the results inside the Section5.

\section{B. Experiments on Classroom}

on this example, all round element appearances can be visible that could help us with convincing the STN from our proposed form. For faces more number one than 200 pixels in tallness, tight-fitted facial pics are taken on the identical time as a few setting data is joined for faces extra little than forty pixels in stature, as setting is a huge problem for seeing little faces. The combination of the systems referenced above are accomplished in computerized way. Triumphing systems modified into executed in urgent examinations. the ones fashions have massive type of parameters in like way they're tuned on $224 \times 224$ or $299 \times 299$ photograph sizes. The removed countenances from passage have a modern-day duration of $120 \times 117$ and upsampling the appearances in consistently fundamental models impacts the facial highlights. Our confirmation model is humbler showed up particularly in association with top level plans and on account of less number of parameters related to less structuring pictures, our model doesn't encounter the faulty impacts of overfitting.

Structure: The structure utilized on get together room information is acceptably modified sort of the Table1. The key trade is done at the final completely related layers (FC5) to plan and test on amphitheater facts. thinking about the understudy quantity.

\section{System and Training Information}

For our usage, we've got got had been given used Keras with Theano backend as our impedance situation on a shape that has Intels Xeon 3.07GHz processor,2 4GBRAM, and 1 Nvidia Quadro6000 GPU with 448 Cuda facilities. The goal or event artwork used on this paper is obvious pass entropy. again propagation figuring is carried out to repair the stores of the CNNs. Stochastic affinity weave (SGD) test is completed to find out the nearby through using minima for this citing cum classification trouble.

\section{RESULTS AND DISCUSSION}

\section{A. On LFW Dataset}

The STN Network perceives how to change the appearances with a persuading objective that the scene defined close to the end gets obliged. 
Table 2 Comparison of face verification shows up

\begin{tabular}{l|l|l|l}
\hline Methods & $\begin{array}{l}\text { Train set } \\
\text { (in } \\
\text { millions) }\end{array}$ & Database & $\begin{array}{l}\text { Recognitio } \\
\text { n accuracy } \\
(\%)\end{array}$ \\
\hline Deep Face [16] & $4 \mathrm{M}$ & LFW & 97.35 \\
\hline FaceNet [12] & $200 \mathrm{M}$ & LFW & 99.63 \\
\hline DeepID2+ [15] & $0.2 \mathrm{M}$ & LFW & 99.47 \\
\hline $\begin{array}{l}\text { Alignment } \\
\text { Learning [19] }\end{array}$ & $0.46 \mathrm{M}$ & LFW & 99.08 \\
\hline Ours & $0.55 \mathrm{M}$ & LFW & 98.77 \\
\hline Ours & 16 images & $\begin{array}{l}\text { Lecture } \\
\text { Hall }\end{array}$ & 100 \\
\hline
\end{tabular}

\section{B. On Lecture Hall Dataset}

The fine-tuning want to keep records (see Fig.6c) shows that the form has monster sort of proper and exquisite sports or non-clean learning. One capability rationalization is that the structure became given the informed parameters concerning the framework which became used on LFW database. there's a big multifaceted nature some of the picture best among LFW database and theater information. In LFW, there can be no closeness of veritable faces like we've in our social illegal courting sitting place statistics as a way to get from the beyond shape there is notifiin a role weight updation which has the primary horrifying impact in the requirements preserve information. within the celebration room data, we've got got seen that STN couldn't make any significant development. thru using a massive facet a terrific bit of the faces are frontal so chart isn't always required for an much less costly interest shape. A scramble of the foreseen face photos are confirmed up inside the Fig.7. From this figure, you'll be capable of see our assertion plan works thoroughly in closeness of slight, reputation quo mess, present shape, and plenty of others. The veritable face, i.e, Fig.7b grow to be interested by blanketed setting and great face, as an example. The intermixing of this form is all around snappier at the same time as it's miles given the pointy parameters on LFW database get numerous facts approximately. The going with figures be part of the advent of our shape within the course of filtering via and finding out. It has taken excellent 60 emphasess to appearance the complete of the 14 appearances with one hundred\% exactness. Most through a huge edge of the obvious appearances may be frontal in test struggle, so the impact of STN stays ignored for this condition.

Table 3 Effect of STN on face verification execution

\begin{tabular}{l|l|l}
\hline Method & Database & $\begin{array}{l}\text { Recogrition } \\
\text { accuracy (\%) }\end{array}$ \\
\hline Without STN & LFW & 96.33 \\
\hline With STN & LFW & 98.61 \\
\hline Without STN & Lecture Hall & 100 \\
\hline With STN & Lecture Hall & 100 \\
\hline
\end{tabular}
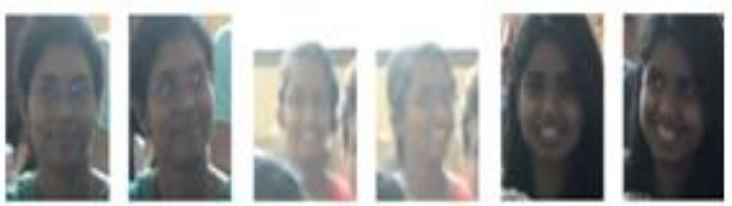

d)

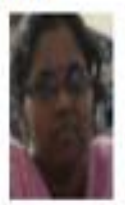

e)

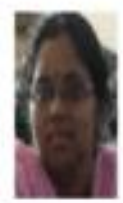

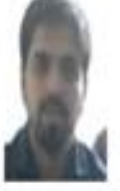

f)

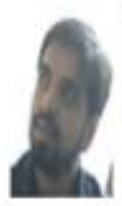

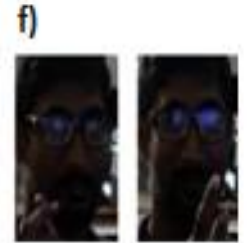

Fig. 6 Recognition output. Left side: Trained face, Right side: Test face

\section{CONCLUSION AND FUTURE WORK}

We have appreciated a totally face clarification what's more as changed intrigue structure utilizing spatial transformer sort out and a little check framework. The structure has achieved 98.61\% verification precision in the LFW database and the organized version in this take a look at have emerge as completed to fine-tune in get together element information. size of readied version was $132 \mathrm{MB}$, it could controlled a microchip or raspberry-pi. The form will pass on the opportunity rankings of the prevailing evaluations from the were given photographs or information.

In future, we need to be part of sharp exam making use of essential analyzing shape with this framework. this can make assessment of a specific beauty and it's going to reveal which topics, time, systems pull in more concept of the understudies. Checking feeling assessment form will assist the group of workers with enhancing or alternate their approach framework.

\section{REFERENCES}

1. Hassaballah, M., Aly, S.: Face recognition: challenges, achievements and future directions. IET Comput. Vis. 9(4), 614-626 (2015)

2. Chintalapati, S., Raghunadh, M.: Automated attendance management system based on face recognition algorithms. In: IEEE Internationa Conference on Computational Intelligence and Computing Research (ICCIC), pp. 1-5. IEEE (2013)

3. Rekha, E., Ramaprasad, P.: An efficient automated attendance management system based on eigen face recognition. In: 7th International Conference on Cloud Computing, Data Science and Engineering-Confluence, pp. 605-608. IEEE (2017)

4. Wagh, P., Thakare, R., Chaudhari, J., Patil, S.: Attendance system based on face recognition using eigen face and pca algorithms. In: International Conference on Green Computing and Internet of Things (ICGCIoT), pp. 303-308. IEEE (2015)

5. Lukas,S.,Mitra,A.R.,Desanti,R.I.,Krisnadi,D.: Student attendance system in classroom using face recognition technique. In: International Conference on Information and Communication Technology Convergence (ICTC), pp. 1032-1035. IEEE (2016)

6. Hu, P., Ramanan, D.: Finding tiny faces. In: 2017 IEEE Conference on Computer Vision and Pattern Recognition (CVPR), pp. 1522-1530 IEEE (2017)

7. He, K., Zhang, X., Ren, S., Sun, J.: Deep residual learning for image recognition. Proc. IEEE Conf. Comput. Vis. Pattern Recognit. 2016, 770-778 (2016)

8. Schroff, F., Kalenichenko, D., Philbin, J.: Facenet: A unified embedding for face recognition and clustering. In: Proceedings of the IEEE Conference on Computer Vision and Pattern Recognition, pp. 815-823 (2015) 
9. Taigman, Y., Yang, M., Ranzato, M., Wolf, L.: Deepface: closing the gap to human-level performance in face verification.Proc.IEEEConf.Comput.Vis.PatternRecognit.1701-1708 (2014)

2. 10.Zhu, X., Lei, Z., Liu, X., Shi, H., Li, S.Z.: Face alignment across large poses: A 3d solution. Proc. IEEE Conf. Comput. Vis. Pattern Recognit. 146-155 (2016)

1. Jaderberg, M., Simonyan, K., Zisserman, A., et al.: Spatial transformer networks. Adv. Neural Inf. Process. Syst. 2017-2025 (2015)

2. Rashid RA, Mahalin NH, Sarijari MA, Abdul Aziz A (2008) Security system using biometric technology: design and implementation of Voice Recognition System (VRS). In: International conference on computer and communication engineering, 2008.ICCCE2008.IEEE,pp898-902

3. Dehghani A, Ghassabi Z, Moghddam HA, Moin MS (2013) Human recognition based on retinal images and using new similarity function. EURASIP J Image Video Process 1:1-10

4. Cappelli R, Maio D, Maltoni D, Wayman JL, Jain AK (2006) Performance evaluation of fingerprint verification systems. IEEE Trans Pattern Anal Mach Intell 28(1):3-18

5. Joseph J, Zacharia KP (2013) Automatic attendance management system using face recognition

6. Zhu J, Yu YL (1994) Face recognition with eigenface. IEEE international conference on industrial technology, pp 434-438

7. RoshanTharanga JG, Samarakoon SMSC, Karunarathne TAP, Liyanage KLPM, Gamage MPAW, Perera D (2013) Smart attendance using real time face recognition (smart-fr). SAITM Research Symposium on Engineering Advancements 2013

8. Chintalapati S, Raghunadh MV (2013) Automated attendance management system based on face recognition algorithms. In: 2013 IEEE international conference on computational intelligence and computing research (ICCIC). IEEE, pp 1-5

9. Javed A (2013) Face recognition based on principal component analysis. Int J Image Graph Sig Process 5(2):38

10. Kawaguchi Y, Shoji T, Weijane LIN, Kakusho K, Minoh M (2005) Face recognition-based lecture attendance system. In: The 3rd AEARU workshop on network education, pp 70-75

11. Viola, P., Jones, M.: Rapid object detection using a boosted cascade of simple features. In: Proceedings of the 2001 IEEE Computer Society Conference on Computer Vision and Pattern Recognition CVPR 2001, pp. I-I. IEEE (2001)

12. Lu, C., Tang, X.: Surpassing human-level face verification performance on lfw with gaussianface. AAAI, 3811-3819 (2015)

13. Sun,Y.,Chen,Y.,Wang,X.,Tang,X.:Deeplearning face representation by joint identification verification. In: Advances in neural information processing systems, pp. 1988-1996 (2014)

14. Sun, Y., Liang, D., Wang, X., Tang, X.: Deepid3: face recognition with very deep neural networks (2015). arXiv:1502.00873

15. Sun, Y., Wang, X., Tang, X.: Deeply learned face representations are sparse, selective, and robust. Proc. IEEE Conf. Comput. Vis. Pattern Recognit. 2892-2900 (2015)

16. Zhong,Y.,Chen,J.,Huang,B.:Towards end-to-end face recognition through alignment learning (2017). arXiv:1701.07174

17. Huang, G.B., Ramesh, M., Berg, T., Learned-Miller, E.: Labeled faces in the wild: A database for studying face recognition in unconstrained environments. Technical report, Technical Report 07-49, University of Massachusetts, Amherst (2007)

18. Hassner,T.,Harel,S.,Paz,E.,Enbar,R.:Effective face frontalization in unconstrained images. Proc. IEEE Conf. Comput. Vis. Pattern Recognit. 7, 4295-4304 (2015) 